\title{
Diet and Addiction: Interview with a Former Food, Pornography, and Alcohol Addict
}

Tro Kalayjian

Tro@DoctorTro.com

Brian Lenzkes

blenzkes@gmail.com

Follow this and additional works at: https://digitalcommons.uri.edu/dignity

Part of the Carbohydrates Commons, Community Health Commons, Community Health and

Preventive Medicine Commons, Dietetics and Clinical Nutrition Commons, Family Medicine Commons, Internal Medicine Commons, Medical Education Commons, Medical Humanities Commons, Primary Care Commons, and the Substance Abuse and Addiction Commons

\section{Recommended Citation}

Kalayjian, Tro and Lenzkes, Brian (2019) "Diet and Addiction: Interview with a Former Food, Pornography, and Alcohol Addict," Dignity: A Journal of Analysis of Exploitation and Violence: Vol. 4: Iss. 1, Article 8. https://doi.org/10.23860/dignity.2019.04.01.08

This Frontline Report is brought to you for free and open access by DigitalCommons@URI. It has been accepted for inclusion in Dignity: A Journal of Analysis of Exploitation and Violence by an authorized editor of DigitalCommons@URI. For more information, please contact digitalcommons-group@uri.edu. 


\title{
Diet and Addiction: Interview with a Former Food, Pornography, and Alcohol Addict
}

\author{
Abstract \\ Drs. Tro Kalayjian (Tapan, New York) and Brian Lenzkes (Santee, California) talk to Matt about his \\ struggles with food, pornography, and alcohol addiction, and how changing his diet contributed to his \\ recovery from his addictions. This report is excerpted from the audio podcast LowCarbMD, Episode 13 \\ (https://itunes.apple.com/us/podcast/low-carb-md-podcast/ ), January 30, 2019). This podcast has filled \\ us with immense hope for those struggling with addiction.

\section{Keywords} \\ addiction, food, pornography, alcohol, diet, low carbohydrate, ketogenic diet

\section{Creative Commons License} \\ c) (i) $\Theta$ \\ This work is licensed under a Creative Commons Attribution-Noncommercial-No Derivative Works 4.0 \\ License.

\section{Acknowledgements} \\ Dignity thanks the following students at the University of Rhode Island for their assistance in transcribing \\ and editing this podcast. Sarah Gladstone, a major in political science and gender and women's studies; \\ and Emily Ramos, a major in human development and family studies and gender and women's studies.
}


DIGNITY

Volume 4, Issue 1, Article 8, 2019
A JOURNAL ON

SEXUAL EXPLOITATION

AND VIOLENCE

\title{
DIET AND ADDICTION: INTERVIEW WITH A FORMER FOOD, PORNOGRAPHY, AND ALCOHOL ADDICT \\ Tro Kalayjian, M.D. \\ Tappan, New York, USA
}

Brian Lenzkes, M.D.

San Diego, California, USA

\begin{abstract}
Drs. Tro Kalayjian (Tapan, New York) and Brian Lenzkes (Santee, California) talk to Matt about his struggles with food, pornography, and alcohol addiction, and how changing his diet contributed to his recovery from his addictions. This report is excerpted from the audio podcast LowCarbMD, Episode 13 (https://itunes.apple.com/us/podcast/low-carb-mdpodcast/ ), January 30, 2019). This podcast has filled us with immense hope for those struggling with addiction.
\end{abstract}

\section{KEYWORDS}

addiction, food, pornography, alcohol, diet, low carbohydrate, ketogenic diet

$\mathrm{T}$ he following transcript is excerpted from a podcast in which Drs. Tro Kalayjian and Brian Lenzkes interviewed Matt, who talks about his experience with food, pornography, and alcohol addictions, and how a change to a low carb/ketogenic diet assisted him to recover from this addictions.

Lenzkes (Brian): Today, we have a controversial topic; however, this is about a real life and a real story. We have a very courageous guest on today. Tro and I realize we're taking a risk, and we may offend or upset people, but as clinicians (medical doctors) we have an obligation. If we see something and we make observations, it's our job is to say something. We're not claiming to be experts in the area of addiction medicine. We'd love to talk to people who are experts in this area and get their feedback. We are working with a courageous guest. I knew we had to talk to him when I saw his story. Dr. Kalayjian will give you a little background of how we got on the topic of addiction, and what his observations have been clinically.

Kalayjian (Tro): In my practice, I've come to see a lot of different patients who are on a low carb, ketogenic, or carnivore diet. ${ }^{1}$ They found me on the Internet and have sought me out for care, whether that's for cholesterol or other problems. I try

\footnotetext{
${ }^{1}$ The low carb, ketogenic, and carnivore diets are defined by the number of carbohydrates a person eats every day: Low carb is 100 grams or less per day; ketogenic is 20-50 grams per day; a carnivore diet is a low carbohydrate meat-based diet.
} 
to help them. I screen all of my patients. I spend 90 minutes with them on the first visit. I look for food addiction; I look for smoking; I look for drinking; I look for sexual habits; I look for pornography use; I look for gambling. I ask them about seat belts and helmets, and even about fire extinguishers. This is part of my assessment of patients' health.

I started to hear from patients who changed their diet, and as a result their anxiety improved or their depression/depressive symptoms improved, or they're able to not abuse alcohol anymore. They're telling me that they are not using as much pornography. One of the things I have found consistently in my patients on a ketogenic or carnivore diet is that their testosterone has gone up. I made this observation and posted it on the Internet: I said that some of my patients with weight loss and improved diet have increased testosterone levels and they are less inclined to use pornography. In some cases, they report having more sex with their wives or with new partners. Also, their depressive symptoms are much better. I thought this was an interesting observation so I shared it on the Internet. I said "This is what I'm seeing." Lenzkes postulated: Do you think this is an addiction issue? Is this a potential interactivity between sugar addiction (and other addictions) and dopamine? Brian and I talked a little bit about it and decided it could be related.

Lenzkes: It could be their self-esteem is better, so now they're more likely to be with their partner, or the erectile dysfunction is getting better because the testosterone is going up and they feel more capable so they don't need to use pornography, and therefore they're having sex with their partner. I was just speculating on these things. I wasn't making any rash conclusions or saying this is a cure for things. I was making a connection.

I have patients who have been hermits for years and all the sudden they're leaving their house, they're meeting their neighbors, and are doing other stuff after changing their diet only. No medication changes. Isn't that interesting? We all started this diet journey for weight loss, or to reduce insulin resistance and prediabetes. I never even thought about it from this standpoint, but when I have patients returning all the time saying the same things that Tro is saying: "I feel calm." "At work people say I'm really a lot nicer. 'You used to be such as jerk." We are observing all these changes in patients' personalities: less frustration and anger, better coping mechanisms. This is what we are seeing in our practices. We are observing this. We aren't making any conclusions, yet.

Kalayjian: Right. The question is: Are patients just getting their acts together? Did they start a ketogenic diet? Did they try a new lifestyle because they wanted improve their lives? Then other areas of their lives started to improve: they started talking with their wives or girlfriends and so they don't need pornography anymore. Or is there some sort of biochemical change taking place where dopamine is being down regulated? Or are there other changes which caused their depression or anxiety to be reduced? As a result, they can socialize better and they're having better luck, and that's why they are using less pornography. I don't really know what the cause is. Maybe these things are unrelated and it's just a statistical aberration that I'm seeing a series of these patients.

It's an interesting discussion, particularly when people tell us that their mental health is improving on a diet with real food. That's how this started, just sharing observations, and saying: "Hey look, this is what I am seeing," and then finding out that someone else halfway across the world-you, Brian-you're all the way in San 
Diego and I'm in New York--you're seeing the same thing. And then there was an outpouring of people from all over the world saying, "I'm seeing the same thing." We have people online saying: "My bipolar symptoms resolved" or "My depression resolved, and it's been three years. I've adopted a ketogenic or carnivore diet." We have people saying their anxiety is gone. I'm thinking: Is proper nutrition related to mental health?

Brian and I have gotten a lot of heat online over this discussion, and some people have called us "quacks." They are making ad hominem attacks on us. They are not respecting our observations or considering the questions we are raising.

Lenzkes: People are twisting our words. Although we are not addiction specialists, we have dealt with patients with addictions throughout our careers. We see there are common underlying factors. In the case of alcohol: Most people who drink more than they should have underlying anxiety/stress and they are self-medicating with that drug. We see people using cocaine and people who are on the Internet constantly. They may be stressed out, and developing addictions is their way of coping. The question is: Is diet decreasing their stress level? Georgia Ede, a psychiatrist, has written about anxiety getting better on a ketogenic diet (http://www.diagnosisdiet.com).

If this is true, then a ketogenic diet could possibly affect other addictive behaviors. If you listen to LowCarbMD's podcast episode number 10, Dr. Robert Cywes ${ }^{2}$ talks about food as an addiction. At first, I thought: "Wow, he's hardcore." But I listened to his argument that sugar is an addictive substance that is seven times more addictive than cocaine. Although, I don't talk to my patients about pornography, but I do hear that their anxiety gets better, their stress gets better, and their depression gets better. I'm hearing that consistently.

Matt has been courageous enough to talk about his struggles. I want Matt to share his story directly. It is powerful and controversial. It's a tough subject, but I've seen marriages destroyed by pornography. We are seeing increased pornography use and addiction. We'd like to know why.

It's tough stuff. I guarantee you there's tons of people who have the same story, but they're afraid to say anything because no one wants to say they struggle with pornography. In the church it is a huge issue. But no one wants to talk about it - or about extra-marital affairs or alcohol addiction. It is a nasty, ugly subject. So Matt, share your story. Because I think you are courageous, and I appreciate your boldness and willingness to put yourself out there to help other people. That's a hero in my view. So, tell us your story, Matt.

Matt: That's very kind. I just want to thank you guys for doing what you do. I am happy to share. I had already been thinking about writing up my experiences, when Tro put up his Twitter post about his observations. So a little bit of my background. In my life, there's been three really significant addictions: food addiction, pornography addiction, and alcohol addiction.

A little bit of context: I grew up in a religious home. I'm a Christian. My dad was a worship pastor, which means he led the music in the church. He struggled with bipolar disorder. His mother had it. The fact that he was a functional human being was a miracle because he came from an extraordinarily abusive home. I have

${ }^{2}$ http://lowcarbmd.com/episode-10 
to give him credit for that. He struggled with some mighty demons in his life. Between the abuse he suffered as a child and other unresolved stuff, he struggled with food. He overate, and that's where I learned to do it. His emotional swings would mean that home was a very emotionally dynamic place-- very unsafe. You were never sure which version you were going to get when you woke up in the morning: sometimes it was great, sometimes it was terrible, and you never knew, but you got really good at recognizing when it was the scary version. And I developed coping mechanisms around that, ways of dealing with the volatile situation.

I learned that eating made me feel good. Certain foods made me feel really good, especially bread and pizza. I became a carbivore 3 of sorts. I would escape with food. One of my favorite things to eat was a cheap .99 microwave pizza. I'd grab on those those, grate a half to a pound of cheese on top of it, microwave it, and eat it. That gave me a sense of elation for a while. It would make me feel better.

Kalayjian: How old were you then?

Matt: 12.

Kalayjian: To escape what was going on?

Matt: Yes. If I wanted to feel better, and the way to do that was to get a whole bunch of carby [carbohydrate] food. At the time I didn't identify it as carby food. Now, that I'm older, with insight, I can look back and see-bread, cereal, pizza, pasta-all that kind of stuff. I would go watch a movie or TV shows or play video games. I would emotionally check out and kind of ride the carb high. Of course, later, it would make me feel miserable.

I don't have a memory of being thin. I started big, then I got bigger. This cycle of medicating myself with food continued until I was about 17 to 18 years old. At my 'prime'-my heaviest, I weighed 265 pounds on a 5-foot 6-inch frame. I wore 48-inch pants. And I could not run. I had a pathetic hobble. If I ran too much, my thighs would rub together, and I would get bleeding sores on the inside of my thighs. I had to take physical education (PE), unfortunately. It was brutal. My twomile time was 36 minutes to start. A very sad case.

At this time, I was already addicted to masturbation as another form of selfmedicating. I did not have access to pornography at that time. I realize that people fall on both sides of the fence when it comes to masturbation, but if you're addicted to a behavior as a way of medicating your feelings, I would hazard to say that is an addiction. I didn't want to. I felt bad when I did, but I felt like I needed to feel better.

Lenzkes: I've talked to people with bulimia, which is making yourself throw up after eating. While I'm not an expert in this area, they tell me that when they were very stressed, they'd eat because food made them feel better, but then afterwards they'd feel guilty. However, they said the real thing was making themselves throw up because they had a feeling of euphoria after that. It was their way of controlling the stress, and the feeling after throwing up was actually better that the eating. So, what you're saying fits right in.

Matt: So, I got very, very big. I was blessed with a challenge in my senior high school. I had done theater--drama and choir. I wanted to take the lead part in a

3 Someone who eats a diet high in carbohydrates. 
musical. The director said he couldn't cast me in that part because you're too fat. Which was a huge blessing. There was nine months before the try-outs, so I did the standard thing: I was going to eat healthier, eat less, and I'm going to move more. And that worked at that time. Although later I came to the point where it didn't work.

I started running, as much as I could run, and I started eating healthier, but it was just the standard American diet, but the healthy version, just less of it. I was hungry all the time, and I was running for four to eight miles most every day. My knees would kill me; everything killed me, but I was going to get in shape. I dropped down to 185 in nine months. So, it's not like I don't have determination and self-discipline. When it was too cold outside to run, I would literally do a stair step in my garage for 45 minutes or an hour at a time. I would do that to get exercise, so I know about discipline. I know about working your tail off to get something to work, so it wasn't that I wasn't capable of doing that. It wasn't that I wasn't capable of self-control. I could, but addiction is a different animal. Fortunately, I got healthier at that point, but food still had this weird sway over me.

After I got to college and got access to the Internet for the first time, I immediately became heavily addicted to pornography. My food abuse had gone down a bit at this point, and I think that's in large part because I had another stronger form of medicating. I don't think I could put together a string of three days when I didn't binge on pornography. It would be one, two, three hours on the Internet looking at things.

I'm a Christian, so I thought this was wrong. I felt horrible and wretched the moment I was done doing it. I would talk to people; I would confess to people. They would pray for me and say we are going to have accountability. I'd still wrestle with it. This went on for years. I ended up joining a ministry that was a support group-an accountability group--for sexual addicts. That's where I started to learn about the addiction cycle and what was mentally going on in your head as you're struggling with addiction. I learned about dopamine, biochemically what is going on, what is creating this sense of addiction. This was powerful and I started to have a lot more grace for myself because I realized this isn't just me lacking self-control, this was something much more powerful. Having community was tremendously important in helping me heal, but I was still really struggling. I was eating a "healthy American diet" at this point, but I was still struggling with it even though I had really good accountability. I have to say that my wife was incredible. She is just an amazing source of grace and the love of my life. When I was still struggling with pornography, and I got a little bit better, so now I could go one to two weeks at a time without using pornography. When I met my wife-and I don't recommend it as a dating strategy-but, on our first date, I laid out my mess to her about the things I come from. And she came right back at me with her messiness. And I thought, "Ok, this is the right woman. She could deal with reality."

Lenzkes: You were being yourself and transparent. You said, "Look here's me. Here's where I'm at." I'm thinking, and I'm sure other people are thinking: Did you substitute one drug or coping mechanism with another? Did you change the food addiction into pornography addiction? Or do you think it was the timing? I'm just questioning that a little bit. How did that transpire?

Matt: I think that I added it to my addiction tool belt. I had pornography. It would give me a much stronger hit. I would still use food on occasion as a more sanitized form of medicating-it's more socially acceptable. I was in an addiction recovery 
group where I was learning a lot. I was good but I was still struggling. And then I added alcohol. And I say added, because I was still struggling with food and pornography as forms of medicating. I actually didn't take my first drink until I was 24 years old, again, because I came from a highly religious family. I found I really liked alcohol. I loved bourbon. I am from Portland, Oregon, originally, and recently moved to Detroit, Michigan, where we have lots of good beer, wine, and liquor. It grew from having a glass once in a while, to having a glass every day, to having a couple glasses or two of bourbon every night. I started getting defensive about my drinking. If my wife asked me, "How many is that?" I would have a growing feeling of frustration inside: "Why are you asking me? I'm fine!" I wouldn't yell or anything, but I could feel this sense of "Hey leave me alone. I just want to feel better."

Lenzkes: That's very common in addiction. We get annoyed when someone asks us: "Isn't that enough?" We think we can determine that. We are in denial and say that isn't a problem. That's one of the classic signs of addiction. You're drinking even if your wife is upset and it is causing problems at home, but you still keep drinking. That's by definition addiction.

Matt: It's an addiction. Maybe it's not diagnosed, but all the signs are there. At this time, I started to struggle with my weight again. I heard about keto and lowcarb high-fat (LCHF). I started dabbling in this. I tried keto-very strict keto with no cheat days, no cheat nothing. I did this because my weight had started to creep back up. I was back up to 195. I didn't want to go in this direction. I found I could eat an enormous amount of food and not gain weight, but if I ate to satiety, I wouldn't lose weight. This was very frustrating because I didn't want to go hungry again. I started to run again-eight to 12 miles. I was doing that for several months. The dial was not moving. No weight gain; no weight loss. No nothing. It was immensely frustrating. I thought, "This is not okay, I've got to figure this out." I'd been listening to Two Keto Dudes--a fantastic podcast. ${ }^{4}$ They had Amber O'Hearn on who talked about her carnivore diet. ${ }^{5}$ I thought that was crazy talk, but it sounded delicious. This was my first exposure to it, but it wasn't until later I heard more about it and listened to other podcasts where people were laying it out. However, these people sounded really smart and they were very well spoken. So, I decided to do more research on it.

Then, I got a new job. I moved from Portland, Oregon, to Detroit, Michigan. I was in Detroit for two months by myself without my family, as I waited for them to have time to move. I decided to take these two months and try the carnivore diet, and see what happened. Previously, I had zero interest in a carnivore diet from a mental health standpoint. I purely wanted to lose fat, and I didn't want to kill myself doing it. So, I went carnivore, and it was fantastic. I lost weight while being full, which was wonderful. Then about six weeks in, my taste for alcohol started to disappear. That was really weird because I liked bourbon. I wondered: "Why does this not taste good anymore?" I didn't like it anymore. I actually didn't want it. This was the strangest thing because I so enjoyed that sense of bliss and feeling of relaxation that came from drinking from bourbon alcohol. I found I didn't need it anymore. By eating carnivore, my desire for anything sweet or stuff I would typically medicate with was gone. If I was hungry, I wanted to eat real food. I didn't

4 http://2ketodudes.com/

5 https://ketowomanpodcast.com/ 
feel a desire to medicate myself. And life was not less stressful at this point. My wife was having a difficult time with the kids back in Portland. I was powerless to help. I felt constantly frustrated by my inability to help her. So, this was not a lowstress time. We were selling a house and buying a house. I was starting a new job. There were tons of stressors --and I'm alone in Detroit.

Lenzkes: The worst combination of things you can have for recovery.

Matt: If I was going to go on a bender, then this is when I'd do it. I didn't, and I am so immensely grateful for that. As more time went by, my desire to look at pornography in stressful situations also evaporated. I won't say it is completely gone. In fact, this week has been stressful. I may have wanted to check out for a while, but I didn't want to do it at all. That may sound small to most people. But for someone who has struggled with addiction and legitimately been afraid to be alone in their own house for fear of having that gnawing thought at the back of their head: "Hey man, you're alone. You have no accountability. No one will know. You could do that right now." The fact that that voice was gone was a huge deal.

Lenzkes: Matt, if I could interject. I took a lot of heat from people for discussing this topic. For example, there's this guy who claims there are no victims in pornography use. However, when your wife finds out what you're doing.... It's being dishonest. It is not having integrity and honesty. If you don't trust someone and there's an addiction... I've seen marriages fall apart because the guy is sneaking alcohol in the trunk of his car or he has it hidden in the garage. The wife says: "You lied to me. I don't trust you anymore." It's not victimless. I've seen marriages crumble as a result of this lack of trust, especially when your wife has been supportive and loving you. When you're on your own that's when these things are going to happen. When guys are quitting alcohol, I tell them: "Keep busy, volunteer somewhere, stay active, because staying home alone is the worst thing you can do." If you're struggling with obesity you don't have a box of candies around, you're going to find it. You're going to have a weak moment and eat it. Trust me. If I'm an alcoholic, I don't hang out in the bar with my buddies. It's important to create proper boundaries.

Matt: I concur with that. If you are struggling with addiction, the first thing you need to do is get community. You need to find somebody you trust and share with them. Get plugged into community, because healing from addiction does not happen in isolation.

What I found amazing is that since changing my diet, my struggle with these addictions has come down dramatically. It's like the volume has gone from 10 down to like one or a half. It's not a complete absence, but the volume in my head has decreased dramatically. I've also noticed that my temperament has been calmer, and it's not just me saying that. My wife sees it. She says: "You don't swing as hard. When something frustrates you, you don't get as frustrated." I'm not as sensitive to emotional swings. Eating this way has made it easier for me to make healthy choices. I think this is something should be studied in a research trial. Did diet cure my addiction? Absolutely not. Have I found my diet to help me with healing from addiction? Absolutely. We need to approach healing holistically. Your mind is connected to your gut. Something that you ingest will impact how you think. I'm not prescribing a carnivore diet, but I'm saying this is my experience. If you're someone who has been struggling with the noise being really loud in your head from an addiction, this may be something worth trying. 
Lenzkes: Along those lines, some of the biggest critics are saying that diet has zero to do with it. Yet, for example, when grandparents take their grandkids out and let them get hopped up on sugar and then return them to mom and dad. See what mom and dad say: "When Grandma takes them, when they get home, they are a nightmare: They are throwing tantrums, crying." So, to say food and drink have zero effect is irresponsible. Of course, alcohol and drugs have an effect. If sugar has these properties, it is not unreasonable to say that possibly there is a dopamine response to food and snacks we eat when someone is really stressed out after a hard day. It's just a way of managing stress and anxiety just like some people would do with alcohol or drugs. That is why your story is so powerful to me, is it possible that diet has an influence on our mental status?

Kalayjian: There's so much quacky stuff out there. So, when doctors say they are seeing that changes in diet are affecting people's lives, moods, stress, anxiety, and their ability to deal with stress, it can raise eyebrows and make them concerned. But then you turn to the data. There are many articles that show that worsening glycemia in diabetes is associated with more depression, more addiction, and more anxiety. Sugar is associated with poor behavior. Food insecurity is associated with violent behavior, and food quality is associated with risky behavior. Sugar is associated with risky behavior. And that's not even looking into Vitamin B12 and its influence on your mood if you are nutritionally deficient. If you're eating sugary cereals you are not going to be getting the nutrients that you need to be mentally healthy from a dietary nutrients and vitamins. So, food quality and sugar are related to behavior and mental health.

Lenzkes: Addiction is very complicated. Stress and anxiety play a role when it comes to your weight. If you were abused as a child, just not eating sugary food is not going to cure your obesity and depression. A lot of us prescribe antidepressants, anxiolytics, and anxiety medicines to help people so that they can get counseling and work on what the underlying pathology is, which can be caused by problems such as a bipolar parents or alcoholism at home. The question is: do I sedate you with a bunch of meds or can we try making some dietary changes, such as cutting out caffeine which we know causes panic attacks and anxiety. I've had patients admitted to the hospital with atrial fibrillation after drinking energy drinks. Food does have an effect on our physiology. I can't imagine how anyone can say that it doesn't.

We are not saying that diet fixes everything. It is just one component. It's not just about losing weight. If you look at the data on gastric bypass surgery, the divorce rate is unbelievable-a 75 to $85 \%$ divorce rate at two years post-surgery and $90 \%$ divorce rate after five years, when there has been significant weight loss. The divorce rate is so high because there is dysfunction in the relationship. Some people want to keep their spouse obese because they don't want other people to look at them. Or the partner who has lost weight says, "I don't need you anymore."

Kalayjian: Sixty to $70 \%$ of the patients in my practice have a positive score on the Adverse Childhood Experiences (ACE) questionnaire, meaning they have experienced multiple types of childhood trauma, including divorce in the home, depression, suicide in the home, somebody in the home went to jail, and food insecurity. All of these things are highly correlated to chronic disease. A ketogenic diet is not going to make these traumas disappear. However, reducing your sugar intake and having a healthy relationship with food may help your outcomes. This is what I'm seeing. 
Kalayjian: I see the same thing. I have patients that no longer need their anxiolytics after they start a ketogenic diet. The same thing with pornography use. Some people got offended, but that is a way of dealing with stress. Pornography starts out with just looking at a magazine, but then it escalates into crazy, scary stuff. You need more and more to get the same fix. As physicians, we think we have an obligation--a responsibility--to pursue this discussion and inquiry. We are not selling a treatment program.

Kalayjian: We are an addicted society. People tell me that sex and masturbation are completely natural. People have a need for sex, but they end up watching BDSM and Fifty Shades of Gray. However, when you're using pornography 3 to 4 hours a day, you're not doing the things you need to do in your daily life. Same thing with food. We have an innate desire and need for food, but somehow, we end up eating bags of chips and ice-cream bars and cereal-and we never get full. I'm speaking from personal experience. My wife used to hide ice-cream and cereal from me, until I realized what was going on. We are an addicted society. We have basic needs that have been perverted and taken to an extreme and to our self-detriment. I postulate that obesity is food addiction. The boom in pornography use is basically this need and drive for sex that is overdone to self-detriment.

Matt: I want to speak to the addiction and stress. I want to head-off some arguments. For example, some suggest that I was struggling with pornography because I wasn't having enough intimacy with my wife. This is absolutely not the case. The first thing you should know is: I have a wonderful wife. She is satisfied with our marriage and our intimacy. That is not the issue.

For me, pornography was not about the sexual release that came with masturbation. It was about viewing pornography to give myself a sense of escape and relief. The pornography literature discusses the triggering of dopamine release and the high. That is what drives the insatiable need for something new. It was a stress release, not a sexual release. That is important for people to know. Pornography addiction had nothing to do with not being satisfied with my wife. This is important for a spouse to know: If your spouse is struggling with pornography, it has nothing to do with you. It doesn't mean they are not satisfied with you. It's a stress release. I am blessed in my marriage because my wife knew this. I've been very open with her about my struggles. Any time I am struggling with this or I fail, I'm going to let you know. I'm not going to hide it.

One of the things that's been a blessing in my life it that there's nothing about me that my wife doesn't know, which makes it a lot easier to be on a podcast like this talking about what a struggle I had with pornography addiction. I want to speak to spouses of people with pornography addiction: don't think you are failing or coming up short. The odds are good that your spouse was struggling with pornography before they met you. This is how they've learned to deal with stressors in their life. Encourage them to reach out and get community around this.

There are lots of a ministries and different organizations that help people with addiction and recovery. As I said, having community is critical in addiction recovery. I'm not a professional addiction recovery professional. I'm telling you what my experience has been. As my diet changed and my health improved, it has been far easier for me to be reflective and introspective about what is going on in my head, and then to talk it out with my wife. Another thing that is difficult for people when they are struggling with addiction is to work through it. It is helpful to talk through 
that with a trusted friend, a counselor, or a support group. Being able to process what causes me to struggle with addiction is how I'm going to move away from it.

Being in a healthier state-physically-has enabled me to be open with wife, and feel less insecure. When I am in a healthier place and I feel good about myself physically, I have an easier time dealing with the other struggles that are going on in my life. Once my body has healed and I am stronger, I feel in control of my body. I feel in control of my food. I feel in control of me-this physical body. I feel safe in myself. I'm not afraid to be by myself lest I start to struggle with some addition. I think that calm makes it easier to start dealing with external things. When my body and my mind are at war, it makes me more susceptible to falling into some temptation and using an addiction to manage my feelings. When I don't feel in control of myself, I'm going to use external behavior to exert control. I feel bad so I'm going to eat something to get control back and make me feel good, or I'm going to look at pornography because I know how to make myself feel good, and I'll be taking control back of my body. I'll use alcohol to make my mood change. There's an element of needing to feel in control.

Having a healthier diet allowed me to lose weight. I've lost fat. I've lost four inches around my waist so far. I feel great. I feel in control of myself. That's enabled me to have a much healthier response to the external forces coming at me which would normally cause me to have an uncontrollable reaction which would lead to addiction behavior.

Kalayjian: I think what you're talking about is so important. It's like a holistic approach. Everything is in line: your nutrition supporting your mental health, your decreasing stress supporting getting over your addictions. I think people need to hear your story. It's a fascinating topic that we need more research and data on. I think this is a hot button topic that a lot of people don't want to talk about. I really have to thank you for being brave enough to discuss this because most people won't discuss it. Its taboo. So, they won't be able to establish the community you are talking about, and they won't be able to get the support they need. And they won't be able to know that they're aren't the only ones struggling with this.

I think when people hear this, they are going to be blown away. I think they are going to share this around with loved ones who have the same problems. You're so gracious to come on the podcast and be interviewed.

Lenzkes: Your courage gives us courage. We know we'll take heat for this interview. All we are doing is talking about what we are seeing. Let people judge for themselves. Reasonable people can think for themselves. All we do is listen to our patients and their experience.

Matt, do you think you are cured of your addictions?

Matt: Absolutely, not. If I started looking at pornography again, those same addictive behaviors would start to reinforce themselves. If I found a new liquor I liked and started drinking, I would form a new addiction pattern. Cure is the wrong word to use when it comes to addiction. Over time, I developed a dependency to a substance or an activity that gave me a chemical response in my mind that enabled me to control the situation and made me feel better. I'm now addicted to this behavior. I got better. So, I healed, but if I went back, I'd get addicted again.

Lenzkes: No one is cured. We are not cured of obesity. Tro and I are going to have that struggle the rest our lives. When you go through stress, what are your coping 
mechanisms? These are critical issues to get out there. Tro said, "I know what it's like to be that guy that can't buckle his seat belt. I know what it's like to be the one everyone is laughing at at the gym." Some people say, you're fat because your weak and you're lazy. If you have an alcoholic friend, you don't offer them a beer, then assume that if they can't stop after one drink, they are weak.

We have to be sensitive and understanding. For people who have been there, like Tro, myself and you, we can understand more.

Matt: Am I cured? No. Am I living free from? Yes. You can live free from it where it is not in control of you anymore. There is hope for people. Don't get caught up in the idea of being cured of something because that is not what's going to happen. You can be in a place where you are free from it and it does not dominant you anymore.

Lenzkes: Amen. Thank you for your courage to come out in the church. I know it's a huge problem. I'm a Christian myself. I see the struggles. I know what is happening. When you get people going down the wrong path, they don't want to look the right path anymore. They are in shame.

I tell you: A ton of people are going to be helped by this podcast. This is critical information. We hope everyone listening to this podcast has learned something of value today.

\section{ACKNOWLEDGMENTS}

Dignity thanks the following students at the University of Rhode Island for their assistance in transcribing and editing this podcast. Sarah Gladstone, a major in political science and gender and women's studies; and Emily Ramos, a major in human development and family studies and gender and women's studies.

\section{AUTHOR BIOGRAPHIES}

Tro Kalayjian, MD, is a board-certified primary care physician and runs the Medical Weight Loss Center in Rockland and Bergen County, Tappan, New York. He has published case reports on achalasia, binge eating disorder, and food addiction. His therapeutic focus includes diabetes, obesity, hypertension, hyperlipidemia, metabolic syndrome, and polycystic ovary syndrome. He can be followed on Twitter @DoctorTro

Brian J. Lenzkes, MD, is a board-certified internal medicine doctor in Santee, California. He is also a staff physician at the Scripps Mercy Hospital. From 2006-2017 he has received the San Diego County Medical Society, San Diego Magazine Top Doctors Award. He does international volunteer medical work for Medical Outreach to Cuba and Guatemala, El Salvador Medial Outreach with Potter's Field Ministries, and House Build, Mexico, with Canyon View Outreach. He can be followed on Twitter @BrianLenzkes

\section{RECOMMENDED CITATION}

Kalayjian, Tro \& Lenzkes, Brian. (2019). Diet and addiction: Interview with a former food, pornography, and alcohol addict. Dignity: A Journal of Sexual Exploitation and Violence. Vol. 4, Issue 1, Article 8. https://doi.org/10.23860/dignity.2019.04.01.08 Available at http://digitalcommons.uri.edu/dignity/vol4/iss1/8 